\title{
Antiretroviral treatment programmes in Nepal: Problems and barriers
}

\section{Wasti SP1, Simkhada $\mathbf{P}^{2}$, Van Teijlingen $\mathbf{E R}^{3}$}

${ }^{1} \mathrm{PhD}$ Student, Department of Public Health, ${ }^{2}$ Lecturer, Section of Population Health, ${ }^{3}$ Reader in Public Health \& MSc Co-ordinator, University of Aberdeen, UK

\begin{abstract}
Background: Antiretroviral (ARV) drugs have become the cornerstone of HIV (Human Immunodeficiency Virus) care and treatment. Its use has led to a marked reduction in AIDS (Acquired Immune Deficiency Syndrome) related morbidity and mortality. However, more than five years after their introduction few HIV infected people in Nepal are receiving ARVs.

Objective: The main aim of this study is to identify barriers and obstacles to providing and expanding ARV programmes in Nepal.

Materials and methods: A qualitative approach consisting of in-depth interviews with three groups of stakeholders: policy makers, ARV service providers and ARV recipients were carried out. The transcripts were analysed using a thematic approach.

Results: The estimated number of people in need was high compared with people currently receiving ARV in Nepal. With regards to the proper distribution of the ARVs, the main problems identified in the interviews were: lack of infrastructure, lack of human resources, financial constraints, programmatic problems, weak leadership and management at national level, poor cooperation between management structures, geographical barriers, lack of awareness and low uptake of counselling and/or testing, stigmatization and discrimination felt by the health workers and the community, lack of coordination and limited access to services.

Conclusion: Limited resources and administrative capacity coupled with strong underlying needs for services pose serious challenges to the government. Despite this, better use could be made of existing services and resources to help benefit more people from ARV.
\end{abstract}

Key words: Service provision, Antiretroviral Treatment, HIV/AIDS, Programme Management

$\mathrm{T}$ he spread of HIV (Human Immunodeficiency Virus) and AIDS (Acquired Immune Deficiency Syndrome) has reached a pandemic form within a short span of time, affecting 33 million people across the globe, 2.7 million people became infected with the virus and 2 million people died of HIV-related causes ${ }^{1}$.

HIV/AIDS is a major public health concern in $\mathrm{Nepal}^{2}$, since its first case was reported in $1988^{3}$. As of August 2008, the National Centre for AIDS and STD (Sexually Transmitted Disease) Control (NCASC) in Nepal reported that there were 12415 HIV positive people, 2037 People living with AIDS and 505 AIDS cases were reported to have died ${ }^{4}$. With poor surveillance systems and the lack of access to quality voluntary counselling and testing services, these prevalence figures are likely to be a gross under estimate. UNAIDS estimated that 75,000 people were living with HIV/AIDS and 5100 AIDS related deaths had occurred till the year $2006^{5}$.
The key sources of HIV infection were sex workers (48\%), injecting drugs (21\%) and housewives (19\%). Similarly, HIV infection in Nepal mainly is found (80\%) in the younger age groups of 20 to 39 years ${ }^{4}$.

\section{Antiretroviral (ARV) treatment programme in Nepal}

Antiretroviral drugs have become the cornerstone of care and treatment for HIV infected people. Antiretroviral regimens improve survival rates and lower the incidence of opportunistic infections of HIV infected people. The use of ARV has led to a marked reduction in AIDS related morbidity and mortality, in countries

\footnotetext{
Correspondence

Sharada Prasad Wasti

PhD Student

Department of Public Health

University of Aberdeen, Scotland, UK

E-mail: spwasti@abdn.ac.uk
} 
where ARVs are widely available are experiencing clear declines in AIDS related death ${ }^{6}$, this has led to a $70 \%$ decline in deaths due to HIV/AIDS 5 .

The HIV/AIDS treatment programme is relatively new in Nepal. In 2003 the government started giving free ARV drugs in a public hospital and national guidelines for ARV treatment were developed in 2004. According to United Nation General Assembly Special Session (UNGASS), only 1 out of 100 of people with HIV/ AIDS received free ARV from 17 different sites through either the public or private health care system, which is very low as compared to other countries? ${ }^{7}$. However, less development has existed in the area of HIV treatment, care and support despite the fact that the estimated number of PLWHA (People Living with HIV/AIDS) in Nepal is high. So far, no research has been published to establish the range of problems and barriers to the expansion of ARV treatment programme in Nepal.

Other countries have reported problems and barriers to the expansion of ARV services. These include: shortage of human resources, inadequate health infrastructure, lack of funding, inadequate access to treatment and stigma and discrimination. The present research aims to establish current problems and barriers to the expansion of ARV treatment programme in Nepal, including problems in delivering of ARV and barriers to expanding existing treatment programme.

\section{Materials and methods}

This qualitative study used face-to-face interviews with stakeholders. The qualitative approach addresses 'how and why' questions rather than: 'how many?', and examines people in their natural setting, using their own natural set of categories ${ }^{8}$. This method is described as a means for better understanding a complex social phenomenon and it explores new topics and also to probe further into complex issues through methods that are not quantifiable into numbers'. Similarly, this method can be used for its own sake to explore a particular issue when a research problem has not been previously explored..$^{10}$ This method contributes to depth and detail of enquiry and conveys a deeper feeling for the persons studied ${ }^{11}$. In this regards, this methodology seeks to gather the information of problems and barriers to ARV service expansion. Thus, it can best be captured by using this methodology. The interviews were semi-structured; the first author used an interview schedule to ensure all key issues were addressed whilst leaving space adds followup questions if and when appropriate.

Purposive sampling was used for selecting participants. Purposive sampling is often used when the researcher has specific requirements for the sample and picks a subject who meets these strict criteria ${ }^{12}$. However, "there is no hard and fast rule for sample size for qualitative study"13.

A total of 18 respondents of three different stake holders groups were interviewed: five key policy makers; ten ARV service providers ( 4 doctors, 3 nurses and 3 people from Non Government Organizations) and three ARV recipients. ARV service providers and ARV recipient participants were from three $\mathrm{ARV}$ providing institutions and two Non Government Organizations (NGOs) located in central region. The service providers, doctors and nurses involved ARV treatment had commenced their services since the start of these services in Nepal. Similarly, the ARV recipients participating in our study had been taking ARV for over nine months.

Interviews were tape recorded with the consent of the respondents. The interviews were in Nepali and then translated into English for analysis. A thematic analysis was employed to categorise the data.

Before conducting the main study, a pilot study ${ }^{14}$ was conducted with two nursing staffs and a doctor at different hospitals in Kathmandu than the study site to help design appropriate interview schedules and key questions for the main interviews. For each respondent, written consent was obtained after clarifying the objectives of the study prior to the interview with them. Moreover, permission was obtained from the Nepal Health Research Council.

\section{Analysis of results}

The main themes related to problems of and barriers to ARV services provision are listed in Table 1. It should be noted that these themes are not mutually exclusive and that there was considerable overlap between some of the themes.

\section{Problems related to infrastructure}

Inadequate basic infrastructure was a key underlying problem which hinders the current services provision as well as potential expansion of ARV treatment. This theme consisted of four sub-themes (see Table 1).

\section{- Physical facilities and space}

Lack of physical facilities and space were often major limitations to providing appropriate ARV services. Most of the respondents thought that it is not possible to expand ARVs services without improving infrastructure in these hospitals, as the ARV programme had to be incorporated in public hospitals. For example, one doctor stated that:

We are serving ARV treatment in a very difficult way because we are serving in a very congested space. How can we add more patients without place for managing them? (Clinician, Kathmandu) 
PLWHA also stated that hospitals had space problems, for example:

Lab and radiology departments are very rushed with outpatients and inpatients. There is not even waiting area and there is difficulty in maintaining confidentiality for HIV positive people in public hospitals. (PLWHA, outside Kathmandu)

- Diagnostic services

Diagnostic facilities must be available if ARV programmes are to run successfully in Nepal. However, diagnostic services are restricted, especially the ability to do a CD4 count. The CD4 level in cells is needed to diagnose HIV in earlier stage of the disease. The majority of respondents made comments similar to this health care worker:

We do not have our own lab. Blood needs to be sent to central lab and it takes time because whole HIV people are depended on only this central lab for CD4 test where is a rush and it takes more time to get results. (Nursing Staff, Kathmandu)

Policy makers saw a similar problem, for example:

Still we do not have adequate pathology (labs) setup for CD4 cell count and the existing set up has always been complained. (MoH)

One doctor highlighted linked the lack of CD4 count facilities out with Kathmandu with travel issues for patients;

Having CD4 cell count machine is fundamental to start ARV. PLWHAs need to go Kathmandu for CD4 count which is major problem faced by patients and the hospitals to start ARV...it is difficult to cater $A R V$ service with out adequate diagnostic services. (Clinician, outside Kathmandu)

- Lack of staff

ARV treatment is staff intensive as it requires close supervision and monitoring of patient compliance with treatment. Many interviewees agreed there was a shortage of health care workers to make ARV treatment work. One director highlighted the problems of trained manpower.

There is great need for trained, well motivated medical personnel (doctors, nurses, counsellor) to assist in the hospitals and in communities too. (NCASC)

Similarly a doctor highlighted insufficient human resource planning:

There is no additional staff provided by MoHP for ARV service, but NCASC started the programme without planning...we always need to adjust in two places because there is huge pressure on inpatients department and we need to attend them rather than attending to ARV patients. But ARV patients need to be given more time for counselling as well as the need to maintain confidentiality. (Clinician, outside Kathmandu)

Overworked doctors and nurses as well as the frequent transfer of trained staff to other hospitals also hinder the provision of services.

- Financial constraint

Antiretroviral drugs are provided by the government free of charge but development of infrastructure in existing health service is an underlying fundamental problem for the government. Whilst individual patients have difficulty to manage out-of-pocket expenses, such as additional costs incurred through travel, diagnostic tests, nutritional and other users charges. Comments often related to the travel cost and time for people living far away from Kathmandu were also made by the participants, for example:

Not all services are free of charges only ARVs are providing in the central level hospitals and is limited in private organizations but clients are in remote areas. Who will provide non medicine costs? ARVS are a life time treatment. ...Implicit costs are main problems to limit access of ARVS to PLWHAs. (Coordinator, NGO)

One PLWHA highlighted that the cost of travel to services in Kathmandu is more than six (?) times the average daily income of many Nepalese, for example;

So many remote areas people were dying without getting ARVs because they do not have money to come by themselves to hospital. They need money for transportation, diagnostics and living ... (my) bus fare is NRs. 1200 and what about other living and tests cost. If calculated it is a huge amount of cost to us......NCASC is just advertising to provide $A R V$ free of cost but nobody has thought about the cost implication (e.g. travel, diagnostic)... we do not have financial support and there are no ways to earn (PLWHA, Kathmandu).

One policy level interviewee argued that the financial problem is stated in two sides, supply and demand:

In the supplier side government is not able to expand $A R V$ in each and every hospital immediately, which takes huge cost.... on the demand side, additional costs like travel cost, diagnostic test costs are prohibiting the PLWHA to come hospitals and testing their blood which is not possible to arrange free of cost by the Ministry. (MoHP) 
The costs of ARV treatment emerged as a chief concern for all interviewees. HIV is chronic in nature, and when properly treated it requires a lifetime commitment and consequently there is a need to find sustainable funding for treatment programmes.

\section{Problems related to management}

\section{- Leadership}

Strong leadership at all levels of society is crucial for an effective response to the epidemic. Leadership involves personal commitment and concrete actions. Inspiring and empowering leadership at all levels is needed. Most respondents commented on the frequent change in directorship of the NCASC, for example:

Continuous changing of NCASC director is the main hurdle of HIV/AIDS programme management and treatment of PLWHAs. The MoHP should not make the NCASC as a "political football ground" by changing director. (Coordinator, NGO)

Lack of visionary leadership and instability of the director in NCASC .... A new person needs at least six months to know the basic functional activities of the organization but with in one year the director will be changed four times. So how can MoHP/NCASC meet millennium development goals and universal coverage of ARVs for Nepalese people? (Clinician, Kathmandu)

\section{- Cooperation between government and $\mathrm{NGOS}$}

Effective coordination is vital for sustainable programmes different levels of the health system. The health system should not be subdivided into many parts as it decreases its efficiency, as one doctor suggested:

The HIVIAIDS programme itself is not set programme to date, NCASC is not able to carry out good coordination in public (hospitals), private (NGOs) and community-based organizations; but to expand the service, NCASC needs to learn from the ARV success story in Bangkok or Brazil. (Clinician, Kathmandu)

\section{- Health service provision}

A number of interviewees raised the concern that the provision of ARV treatment is not suitable. A policy maker stated that:

Our treatment procedure itself is not suitable, i.e. It is based on a CD4 test. Without this...there is no provision to start ARV....if you based on that protocol we cannot expand ARV service to all the eligible people. (MoHP)

Whilst an interviewee from NCASC highlighted referral and communication problems:

There is no referral mechanism developed in clinical sites...until and unless we make ARVs services accessible. The provider has a good referral mechanism, but we have not seen it to date and there is very poor coordination. (NCASC)

Interviewees did not only refer to the provision of ARV drugs services, but also the lack of counselling, for example:

Most of people do not know they are infected; and so they do not get any treatment or drugs. ..People are diagnosed HIV after very serious conditions, ..providing enough HIV counselling and testing services encourage people to use these services. ..still in many societies of Nepal, has fear of stigma and discrimination remains a serious barrier of VCT (Voluntary Counselling \& Testing) services. (NCASC)

Some interviewees mentioned the general health care problem in Nepal, namely that doctors are not available when they should be, for example:

You know, the doctors and other health personnel are always unavailable in hilly and mountain district hospitals and Primary Healthcare Centres (PHC) in Nepal....... who will refer them to go in hospital for ARV? (PLWHA, Kathmandu)

It was found that PLWHA often had inadequate knowledge about counselling, and counselling and testing services are difficult to access for PLWHA.

\section{Problems related to access}

- Geographical barriers and access

Most interviewees found that distance is a barrier, which needs to be addressed when expanding ARV sites to offer access to all eligible people.

The real ARV needy people are without services and treatment services are only focused in urban areas but we need in (=rural districts) people because how to reach Dhangadi (district) from there, who'll bear their additional cost? (Coordinator, NGO)

Many PLWHAs are living without treatment......... the existing ARV institutions are mostly constrained in urban areas ... we need ARV treatment in rural districts because it is difficult to reach existing ARV institutions from remote areas and also it takes a while...... there are no road, no vehicles in hilly districts. (Coordinator, NGO)

Similarly, participants stated that there is very limited access to ARVs treatment for PLWHA. Again rural areas were seen as particularly problematic:

In so many remote areas people are dying without getting ARVs ... they do not have access to the hospital. ARV is limited to only a few hospitals which 
are all in urban areas. Think about $80 \%$ people that are living in rural areas, how to access to all PLWHA? (PLWHA, Kathmandu)

\section{Problems related to stigma}

Stigma found to discourage people from coming for testing and majority of respondents stated that;

Still rural people do not want to go to the hospital and laboratory to test their status because they say that people will recognize them as a HIV positive person. (PLWHA, Kathmandu)

Others refer to the general ignorance still portrayed by some people who refer to HIV as the Bombay disease:

Still Mid- Far western region people (Doti, Achham districts) regard HIV as a "Bombay Disease".... one patients came and asked me....doctor give me injection for Bombay Disease. (MoHP)
Nonetheless, stigma found to discourage people from coming for testing. For example;

Why are rural people still not diagnosed and on ARV treatment? Because most of them do not know where to go and they are not ready to ask for information in the community because people will take it negatively about their status and he/she will be avoided them from society due their HIV status. (Clinician, Kathmandu)

Still HIV positive people in Nepal are perceived negatively...sex workers, drug users in Nepal are often taken negatively and discriminated. (NCASC)

High level discrimination against HIV infected persons, identification and willingness to undergo diagnostic procedures puts a serious barrier for many people.

Table 1: Key problems and barriers to improved ARV delivery in Nepal

1. Problem related to infrastructure:

- $\quad$ Physical facilities and space

- Diagnostic services

- $\quad$ Staffing

- Financial constraint

2. Problems related management

- Weak leadership

- Cooperation between Government and NGOs

- Health services provision (ARV provision, counselling, testing)

3. Problems related to access

- Geographical barriers and poor access

4. Problems related to stigma

\section{Discussion}

This study highlights three key factors: resource constraint, cultural/societal issues and management. Each factor is discussed in more detail below:

\section{Resource constraint}

ARV treatment is a complex process which needs continued close supervision by health professionals through laboratory facilities. Most respondents stated that there were major infrastructural problems and barriers to expansion of ARV services, including, lack of proper laboratory services (e.g. CD4 machine \& space) There was only one functioning CD4 counting machine in Kathmandu. Clients from other parts have to travel to the capital in order to get a CD4 cell count, which they need to qualify for ARV drugs and to monitor their treatment.

Infrastructural problems were also faced in Kenya, Tanzania, Uganda and Mozambique ${ }^{15}$ and inadequate laboratory facilities and poor patient care infrastructures were major barriers to expansion of treatment in Africa $^{16}$. Similarly, shortage of human resources is a global issue in most resource-constrained countries ${ }^{17}$. In Nepal we found lack of staff and overworked doctors and nurses. At the same time, there was frequent transfer of trained health personnel. Shortage of appropriately trained health care staff is also reported in countries in Asia (e.g. China, India, Thailand) and Sub-Saharan 
Africa (e.g. Kenya, Tanzania, Uganda, Ghana) ${ }^{18,19,} 20,21$. Thus, adequate trained staff should be managed first before services are expanded otherwise it will be very challenging to provide services to the increasing number of PLWHA. Adequately trained human resources are an important component for the delivery of quality health services. Frequent absence of health personnel in districts is another general health system problem stated by interviewees. This might be due to poor working environment, poor incentives and lack of opportunities for career development as well as insecurity of life in districts due to violence.

Antiretroviral drugs are provided by Nepal government free of charge but the interviewees argued that patients are burdened by the additional costs (transportation costs, diagnostic costs etc.). One Nepalese study revealed that the economic conditions of PLWHA's households are worse than non-PLWHA's households ${ }^{22}$. Poverty affects all aspects of care, including patient's ability to pay for transport fares, food and diagnostic tests. The majority of interviewees worried about these costs in the light of the chronic nature of HIV disease, and the cost associated with long-term treatment. Similar findings were reported in Thailand where pre and post ARV test costs were major constraints to expanding $\mathrm{ARVs}^{21}$ and Botswana where, 12 percent of ARV clients did not receive $A R V s$ treatment because they could not afford to pay for transport ${ }^{23}$. These findings suggest that many HIV positive people have significant non-drugs related financial problems, even though their government is providing ARV free of costs.

The government has limited funds for the expansion of infrastructure, human resources and operating costs. MoHP is the prime provider of funds funded of the health sector and a substantial contribution is made by NGOs in $\mathrm{Nepal}^{24}$. Furthermore, an expansion of treatment sites will not be possible without sustainable financing for the expansion of infrastructures and capacity building as well as addressing implicit costs of the ARV clients.

\section{Socio-cultural problem}

Interviewees reported that stigma and discrimination were major problems and barriers to the expansion of ARV to remote districts in Nepal. Moreover, high levels stigma and discrimination against PLWHA, leads to an unwillingness to reveal HIV status and/or to undergo diagnostic and treatment procedures. Thus PLWHA not coming forward to access ARV services is deeply rooted in social fears, misconceptions and cultural believes. Poor information, fear of discrimination and stigmatization from the health personnel as well as the community are probably the key factors discouraging people from being tested and taking up treatment. Botswana faced a huge stigma problem that posed a barrier for patients who could not take their treatments at home or at work due to fear of detection and for patients who felt uncomfortable going to the hospital for testing and medication refills as a result of confidentiality concerns ${ }^{25,26}$.

In Nepal most of the people living with HIV/AIDS do not know if they are infected and so many PLWHA may continue to be engaging in unsafe sexual practices. This might be associated with stigma and discrimination against these people. Other high risk groups are also practicing these norms and do not go to test and seek treatment ${ }^{27}$. Thus, Nepalese people continue to perceive HIV/AIDS negatively. PLWHA hide their disease, due to the fear of the separation and the stigma sculptured by the mass media - i.e. HIV is a bad person's disease. PLWHA and commercial sex workers are socially and culturally rejected as bad characters, something which directly hinders the utilization of ARV services. Elsewhere, in Senegal, patients hide their medicines due to some of their relatives are still reject them ${ }^{28}$.

Socio-cultural factors are responsible to fuel the spread of HIV/AIDS in most societies at different levels ranging from individual to national and international which have significant impacts on public health. The impact may be socio-cultural and psychological.

Counselling enables a person to cope better with stressful situations, find practical ways to solve problems and make positive decisions regarding own health. Counselling services have a pivotal role in HIV/ AIDS care ${ }^{29}$. HIV counselling and testing is a major starting point for accessing and being informed on HIV/ AIDS related services which will provide psychological support $^{30}$. ARV centres need strong linkages with other clinical services with good referrals and good counselling services so that HIV positive people register for ARV before they reach the late stages of the infection. For good referral, counselling and testing can help promote greater social acceptance of PLWHA. It is argued that widespread uptake of VCT within communities can help "to normalise HIV/AIDS to reduce AIDS related stigma and to raise awareness of the epidemic" $" 31$ and represents a mechanism for referral into care and treatment in health centres ${ }^{32}$. VCT is viewed as a costeffective strategy that can serve as a gateway to most HIV-related services ${ }^{33}$.

Still Nepalese migrant workers communities have low awareness about HIV/AIDS. The study revealed that HIV/AIDS as a "Bombay disease" and still so many PLWHA are living with out adequate knowledge about counselling. Several reasons were associated with the limited number of people knowing their HIV status, disclosing their status and receiving ARV treatments. There are limited numbers of VCT sites and some people may not approach health facilities for testing 
HIV status and in some of the case people are interested to seek test but due to poor referral systems they do not reach the right place.

However just expanding VCT sites and identifying more HIV positive or symptomatic people without having adequate treatment services will have a negative effect. By knowing their status, they will have emotional responses like anger, despair and even may attempt suicide. These emotional responses are normal but counselling can cope with some instances.

\section{Poor leadership}

Strong leadership at all levels of society is crucial for an effective response to the HIV/AIDS management. Leadership involves personal commitment and concrete actions but NCASC is functioning with instability at the top level of management (through frequent changes of director) which is hindering the programme's effectiveness in the long term. According to UNGASS, NCASC is a poorly functioning national coordination mechanism which results in poor policy support ${ }^{34}$. Inspiring and empowering leadership at all levels is needed to transform the national response to HIV and AIDS from a plan into action. Respondents stated that instability at top level management in NCASC is the main problem to hindering further expansion of the programme.

The majority of respondents stated that the HIV/ AIDS programme has still not matured due to frequent change of the NCASC director since its establishment and is directly affecting the continuity of programme implementation. It may have happened due to frequent changes of government and appointment of newly favoured persons due to changing of the health minister. Whilst HIV/AIDS is a prestigious programme which has a lot of opportunities to earn money, it is referred to as a "gold" programme. In this situation, there is a huge competition among government personnel to work in this position.

\section{Strengths and weaknesses}

This in-depth interview study is the first of its kind to bring together the views of the three key stakeholders regarding ARV in Nepal. This study is the first types of study in the field of HIV/AIDS treatment program in Nepal from a management perspectives and which opens a new gateway for further research. All issues were discussed in Nepali language, where all interviewees were actively discussing the issues in natural settings in mother tongue which is strength of this study.

The study has used a qualitative approach with purposive sampling technique. Due to limitations of time and resources we have not included all Nepalese ARV sites in this study. More importantly, our study only included PLWHA who were currently receiving ARV, ignoring
PLWHA who were not receiving treatment. There are limitations to the epidemiological data that is currently available as it is inconsistent and lacking in uniformity. The study has only interviewed the male clients and did not include the female clients which might influence the situation of female PLWHA. However, in spite of these various limitations, approaching a wide-range of different participants and interviewing them gave us a comprehensive set of results.

\section{Conclusions}

Our study revealed that making ARV treatment services available and to expand ARV sites to all ARV eligible people in Nepal is associated with a range of problems and barriers.

DOTS has a good track record for tuberculosis control in Nepal and if the same model for the delivery of ARV treatment services can be made to work at a national level, many lives can be saved and the risk of drugs resistance kept low. There is currently a lack of effective comprehensive ARV provision, especially of programmes that can engage HIV infected people as participants in a full array of treatment services. Efforts to expand ARV services requires a collaborative approach of involving policy level and all stakeholders (health workers, NGOs/INGOs and PLWHAs). There is urgent need to address those problems and strengthen the whole spectrums of health systems through collaborative approach for making ARV services available to all ARV eligible people. This raises the questions towards achievement of the millennium development goals to halt and reverse the spread of HIV/AIDS by 2015.

\section{Recommendations}

It is necessary to strengthen and expand infrastructure (e.g. adequate rooms in existing ARV sites), provide diagnostic facilities in all regional, zonal and district hospitals and make existing ARV sites a "centre of excellence" in a central hospital as well as "one-stopcare" centres.

Perhaps it is possible to establish a system to collect specimen and send these for CD4 cell count in central laboratory rather than sending patients themselves for a CD4 test to Kathmandu.

Frequently unavailability of trained health personnel in and outside Kathmandu is one of the main problems. Thus, it is necessary to find out the cause and make a "package policy" to address why these personnel are frequently leaving their allotted place.

It is necessary to ensure the stability of top level management of NCASC and reduce the frequent replacement. 
NGOs should work at community level aimed at mitigating stigma and discrimination in an effort to create an environment where PLWHA can take ARVs without fear.

As this study was done with a small sample size for limited time period therefore it is necessary to conduct a large scale and more representative quantitative study with a variety of health professionals, private (NGOS/ INGOs) representatives, more PLWHA on ARV and also including the family members of PLWHA.

In order to minimize the financial burden to PLWHAs, there should be either provision for allowances to receive ARV drugs or ARV treatment should consider home delivery by NGOs. Although we recognise that this in itself may increase the risk of stigma for PLWHA in their own community.

Perhaps it is possible to accurately determine the number of ARV eligible clients (epidemiology) in Nepal and the main areas in which they live in order to develop a planned ARV services.

\section{References}

1. UNAIDS. Report on the Global AIDS Epidemic 2008: Status of the global HIV epidemic. Geneva: UNAIDS; 2006.

2. MoHP. Adolescent Health and Development in Nepal: Status, Issues, Programmes and Challenges, a Country Profile. Kathmandu: Ministry of Health and Population; 2005. p. 34.

3. Subedi BK, Gurabacharya VL, Thapa K. Seasonal Migration in Western Nepal and its Relation to HIV Transmission. Journal of Nepal Medical Association. 1992;33:30-3.

4. NCASC. Cumulative HIV/AIDS Situation of Nepal. Ministry of Health: National Centre for AIDS and STD Control; 2008.

5. WHO/UNAIDS. Report on the Global AIDS Epidemic 2006: Country Profiles. Geneva: UNAIDS; 2006.

6. Porter, K. et al. Determinants of Survival Following HIV-1 Seroconversion after the Introduction of HAART. The Lancet. 2003;362:1267 - 74 .

7. NCASC. List of Care Providing ART Services. Ministry of Health: National Centre for AIDS and STD Control; 2008.

8. Van Teijlingen E, Forrest K. The Range of Qualitative Research Methods in Family Planning and Reproductive Health Care. Journal of Family Planning and Reproductive Health Care. 2004; 30 (3):171-3.

9. Bowling A. Research Methods in Health: Investigating Health and Health Services. 2nd edition. London, Open University Press; 2002. p. 352-4.

10. Keenan KF, Van Teijlingen E. The Quality of Qualitative Research in Family Planning and Reproductive Health Care. Journal of Family Planning and Reproductive Health Care. 2004; 30 (4):257-9.

11. McDowell, MacLeam L. Blending Qualitative and Quantitative Study Methods in Health Services Research. Health Informatics Journal. 1998; 4:15.

12. Panack EA, Thompson CB. Sampling Methods: Selecting Your Subjects, Air Medical Journal. 2007; 26(2):75-8.

13. Oppenheim A. Questionnaire Design, Interviewing and Attitude Measurement. London: Heinemann Educational Books; 1996.

14. Teijlingen van E, Hundley V. Pilot studies in family planning and reproductive health care. Journal of Family Planning \& Reproductive Health Care. 2005; 31(3):219-21.

15. Attawell K, Mundy J. Provision of Antiretroviral Therapy in Resource Limited Settings: a Review of Experience up to August 2003. London: WHO and the UK's Department for International Development, DFID Health System Resource Centre; 2003.

16. Commission on HIV/AIDS and Government in Africa (CHG) [homepage on Internet]. Scaling up AIDS Treatment in Africa: Issues and Challenges; 2007. http://www.uneca.org/ CHGA (Cited on: June 2007).

17. UNAIDS. Guidelines for Managing the HIV/ AIDS Supply Chain. Geneva: UNAIDS; 2006.

18. Sui C. China Starts Offering Free AIDS Drugs but Lacks Doctors to Administer Them[home page on the internet]; 2003 [cited on June 2007]. Available from: http://www.aegis.com / default. asp? req=http ://www.aegis.com/news / afp /2003/AF030781.html

19. Bhata R, Maheshwari SK, Saha S. Treating HIV/AIDS Patients in India with Antiretroviral Therapy: a Management Challenge. Indian Institute of Management Ahmedabad; 2004. [Book on the Internet] http://www.iimahd. ernet.in/ publications / data/2004-06-03rbhat. pdf (Cited on: May 2007).

20. AVERT. Providing Drug Treatment for Millions [homepage on the Internet]; 2007. [cited on march 2007]. Available from: http://www.avert. org/drugtreatment.htm

21. Angsulee NK, Sringemyuang L, Haritavorn N. Beyond the Target: Assessment of Public and Private ARV Treatment Programs Thailand 
Country Working Paper. Netherlands: Health Action International Group; 2006. p. 50.

22. CREHPA, NIDI. Out of Pocket Expenditures on Sexual and Reproductive Health and HIV/ AIDS Among the Urban Population of Nepal. Nepal: Centre for Research on Environment Health and Population Activities (CREHPA) \& Netherlands Interdisciplinary Demographic Institute (NIDI); 2006. p.50-67.

23. Kgatiwane J, Ogenyi R, Ekezie C, Madaki HN, Moyo S, Moroka TM. Factors that Facilitate or Constrain Adherence to Antiretroviral Therapy Among Adults at Four Public Health Facilities in Botswana : a Pre-intervention Study [book on the Internet]. Geneva: WHO; 2007. [cited on July 2007]. Available on: http://mednet3.who. int/PRDUC/Book/Botswana_FINAL.pdf

24. MoH. Public Expenditure Review of the Health Sector. HMGN - DFID: British Council Nepal; 2004.

25. Weiser S, et al. Barriers to Antiretroviral Adherence for Patients Living with HIV Infection and AIDS in Botswana. Journal of Acquire Immune Deficiency Syndrome; 2003; 34 (3):281-8.

26. UNAIDS. Drugs Use and HIV Vulnerability: Policy Research Study in Asia, Task Force on Drug Use and HIV Vulnerability. Thailand: UNAIDS; 2000.

27. UNAIDS/NCASC. The HIV/AIDS/STD Situation and the National Response in Nepal: Country Report. Kathmandu: UNAIDS, NCASC; 2004.
28. Furber AS, Hodgson IJ, Desclaux A, Mukasa D. Barriers to better care for people with AIDS in developing countries. British Medical Journal. 2004; 329:1281-3.

29. Gilks CF. HIV Care in Non-Industrialised Countries. British Council: British Medical Bulletin. 2001; 58:171-6.

30. Lamptey PR, Johnson JL, Khan M. The Global Challenge of HIV and AIDS, Population Bulletin. Population Reference Bureau. 2006; 16(1):19.

31. UNAIDS. The Impact of Voluntary Counselling and Testing: a Global Review of the Benefits and Challenges. Geneva: UNAIDS; 2001. p. 46.

32. Birdsal K, Haliyiannism H, Nkosi Z, Parker W. Voluntary Counselling and Testing (VCT) in South Africa: Analysis of Calls to the National AIDS Helpline. Johannesburg: Centre for AIDS Development Research and Evaluation; 2004. p. 1 - 8 .

33. WHO. Entry Points to Antiretroviral Treatment [homepage on the Internet]. WHO; 2003. [cited on August 2007]. Available on: http:/www. who.int/3by5/publications/briefs/en/entry_ points.pdf

34. United Nations General Assembly. National Report: Nepal [homepage on teh Internet]. 2005 [cited on February 2007]. Available from: http:// data.unaids.org/pub/Report/2006/2006country_ progress_report_nepal_en.pdf) 